\title{
Ghrelin Aggravates Prostate Enlargement in Rats with Testosterone-Induced Benign Prostatic Hyperplasia, Stromal Cell Proliferation, and Smooth Muscle Contraction in Human Prostate Tissues
}

\author{
Xiaolong Wang, ${ }^{1}$ Yiming Wang, ${ }^{1,2}$ Christian Gratzke, ${ }^{1,3}$ Christian Sterr, ${ }^{1}$ Qingfeng Yu, \\ Bingsheng Li, ${ }^{1}$ Frank Strittmatter, ${ }^{1}$ Annika Herlemann, ${ }^{1}$ Alexander Tamalunas, ${ }^{1}$ \\ Beata Rutz, ${ }^{1}$ Anna Ciotkowska, ${ }^{1}$ Raphaela Waidelich, ${ }^{1}$ Chunxiao Liu, ${ }^{2}$ Christian G. Stief, ${ }^{1}$ \\ and Martin Hennenberg ${ }^{1}{ }^{1}$ \\ ${ }^{1}$ Department of Urology, Ludwig-Maximilians University, Munich, Germany \\ ${ }^{2}$ Department of Urology, Zhujiang Hospital, Southern Medical University, Guangzhou, China \\ ${ }^{3}$ Department of Urology, University of Freiburg, Freiburg, Germany
}

Correspondence should be addressed to Martin Hennenberg; martin.hennenberg@med.uni-muenchen.de

Received 18 June 2019; Revised 1 October 2019; Accepted 30 October 2019; Published 22 November 2019

Academic Editor: Gerardo García-Rivas

Copyright ( $\odot 2019$ Xiaolong Wang et al. This is an open access article distributed under the Creative Commons Attribution License, which permits unrestricted use, distribution, and reproduction in any medium, provided the original work is properly cited.

Epidemiologic studies revealed a context between lower urinary tract symptoms (LUTS) suggestive of benign prostatic hyperplasia $(\mathrm{BPH})$ and metabolic syndrome. However, molecular mechanisms underlying this relationship are largely unknown. Prostate enlargement and increased prostate smooth muscle tone are important factors in the pathophysiology of LUTS suggestive of $\mathrm{BPH}$. In the present study, we studied effects of the metabolic hormone ghrelin on prostate enlargement in rats with experimentally induced $\mathrm{BPH}$, growth of cultured stromal cells from human prostate (WPMY-1), and smooth muscle contraction of human prostate tissues. Ghrelin $(20 \mathrm{nmol} / \mathrm{kg}$ daily, p.o., 2 weeks) increased prostate size in rats with testosteroneinduced BPH. Microarray identified 114 ghrelin-upregulated genes (2-fold or more) in these prostates, with possible roles in growth, smooth muscle contraction, or metabolism. 12 genes were selected for further analyses. In human prostate tissues, mRNA levels of 11 of them correlated positively with ghrelin receptor (GHSR) expression, but only two with the degree of BPH. Accordingly, no correlation was evident between GHSR expression level and BPH in human prostate tissues. In WPMY-1 cells, the GHRS agonist MK0677 upregulated 11 of the selected genes. MK0677 induced proliferation of WPMY-1 cells, shown by EdU assay, colony formation, proliferation markers, flow cytometry, and viability. In myographic measurements, GHSR agonists enhanced contractions of human prostate strips. Together, ghrelin may aggravate prostate enlargement, stromal cell growth, and prostate smooth muscle contraction in BPH. Ghrelin may deteriorate urethral obstruction independently from BPH, qualifying the ghrelin system as an attractive new target to be tested for LUTS treatment in BPH.

\section{Introduction}

Benign prostatic hyperplasia (BPH) is commonly associated with lower urinary tract symptoms (LUTS), resulting from urethral obstruction due to prostate enlargement and increased prostate smooth muscle tone [1]. Treatment becomes often inevitable and is aimed (1) at improving symptoms and (2) at preventing BPH progression and com- plications [2]. Widespread options for medical treatment of LUTS suggestive of BPH are $\alpha_{1}$-adrenoceptor antagonists and phosphodiesterase-5 inhibitors, which may improve symptoms by inhibition of prostate smooth muscle contraction, and $5 \alpha$-reductase inhibitors to reduce prostate growth [2]. Combination therapies are commonly applied to address prostate size and symptoms at once [2]. However, available medical therapies have limited efficacy even in mild to 
moderate LUTS [2]. Improvements of symptoms and of urinary flow by $\alpha_{1}$-blockers are restricted to $50 \%[1,3$, 4]. Similarly, the risk of symptomatic progression can be reduced at most by $35-40 \%$ by monotherapy and by $66 \%$ by combination therapies [3].

Epidemiological studies suggested a context between metabolic syndrome and BPH/LUTS [5]. Metabolic syndrome itself and its single components were identified as risk factors for $\mathrm{BPH}$ and LUTS [5]. While this association is well established at a clinical level, molecular links of this relationship are poorly understood. Preclinical studies focused on the role of inflammatory mediators and lipoproteins [5]. Any role of metabolic hormones, which contribute to the metabolic syndrome as well, has not been considered to explain molecular connections between metabolic syndrome and $\mathrm{BPH}[5]$.

Adipokines, including ghrelin or other metabolic hormones play a central role for pathophysiology of the metabolic syndrome. Ghrelin is a metabolic peptide hormone acting by activation of the growth hormone secretagogue receptor 1a (GHSR1a) and probably via additional receptors [6]. Ghrelin increases food intake and body weight [6,7]. At a cellular level, ghrelin induces proliferation, differentiation, and lipid accumulation in adipocytes and preadipocytes [6]. Regulation and promotion of cell cycle in other cell types including smooth muscle cells outside the lower urinary tract have been reported $[6,8,9]$. Most ghrelin functions are attributed to GHSR activation by acyl-ghrelin, while desacyl-ghrelin does not activate the GHSR [6]. In obese subjects with metabolic syndrome, the ratio between acyl- and desacyl-ghrelin is shifted towards acetylated ghrelin, underlining the role of ghrelin for the metabolic syndrome [10]. Considering the relationships between metabolic syndrome and $\mathrm{BPH}$ on the one hand and the role of smooth muscle contraction and prostate growth for LUTS suggestive of $\mathrm{BPH}$ on the other hand, a possible role of the ghrelin system for BPH and LUTS may be assumed. Here, we report effects of ghrelin and GHSR agonists on prostate growth and gene expression in rats with experimentally induced $\mathrm{BPH}$ and on proliferation, gene expression, and smooth muscle contraction in human prostate tissues and in cultured stromal cells.

\section{Materials and Methods}

2.1. Testosterone-Induced BPH in Rats. Procedures in rats were approved by the Animal Experimentation Ethics Committee of the Southern Medical University (SMU), Guangzhou, China. Procedures applied in our study were in accordance with the regulations applying for countries of the European Union. Animal experiments took place in the Laboratory Animal Center, Southern Medical University, Guangzhou, China. Six-week-old male Sprague Dawley rats (180-220 g) were purchased from the Laboratory Animal Center of SMU and housed under controlled conditions of temperature, humidity, and light/dark cycle. Water and food were supplied ad libitum. After $72 \mathrm{~h}$ of accommodation, rats were distributed randomly into three groups ( $n=8 /$ group): (1) a sham-operated group (sham) undergoing sham operation for castration, subcutaneous injection of corn oil, and peroral treatment with vehicle (ghrelin control, distilled water); (2) an androgen-induced $\mathrm{BPH}$ group (BPH) undergoing castration, subcutaneous injection of dihydrotestosterone $(3 \mathrm{mg} / \mathrm{kg})$ for four weeks, and peroral treatment with vehicle (distilled water); and (3) an orally ghrelin-treated group (BPH+ghrelin) undergoing castration, subcutaneous injection of dihydrotestosterone $(3 \mathrm{mg} / \mathrm{kg})$ for four weeks, and peroral treatment with rat ghrelin $(20 \mathrm{nmol} / \mathrm{kg})$ (Tocris, Bristol, UK) for two weeks, starting two weeks after initiation of testosterone treatment. Injections and oral treatments were performed once daily, starting after $72 \mathrm{~h}$ of the surgical procedure. A complete randomization process was carried out so that every experimental unit had an equal chance of receiving each treatment. Ghrelin was dissolved in distilled water and applied by gavage. In previous studies, application of 12 or $16 \mathrm{nmol} / \mathrm{kg}$ of ghrelin induced growth hormone release and functional effects in vivo in rats [11-13]. After 4 weeks, rats were sacrificed by cervical dislocation, following anesthesia using carbon dioxide prior to cervical dislocation, and prostates were removed, shock frozen, and stored at $-80^{\circ} \mathrm{C}$ until microarray analyses. Body weight was measured before the experiments and after the 4week treatment and wet weight of the isolated prostate directly following prostatectomy.

2.2. Microarray Analysis. A global gene expression analysis of rat prostates was performed according to the Agilent OneColor Microarray-Based Gene Expression Analysis protocol (Agilent Technologies, Santa Clara, CA, USA). Total RNA was linearly amplified and labeled with Cy3-UTP. Concentration and specific activity of the labeled cRNAs (pmol Cy3/ $/$ g cRNA) were measured by NanoDrop ND-1000. Labeled cRNA was fragmented and diluted with GE hybridization buffer. Hybridized arrays were scanned with the Agilent DNA Microarray Scanner (part number G2505C). Quantile normalization and subsequent data processing were performed with using the GeneSpring GX v12.1 software package (Agilent Technologies).

All data obtained by microarray in this study have been deposited in NCBI's Gene Expression Omnibus and are accessible through the GEO repository with the accession number GSE129561 (https://www.ncbi.nlm.nih.gov/geo/ query/acc.cgi?acc=GSE129561). The data sets could be downloaded from the GEO database.

Selection of genes to categories of interest was performed by definition of predetermined categories. These categories were defined before the experiments. Criteria for selection for subsequent validation in cell culture and human prostate tissues (including correlation analyses) were a 1-fold or higher upregulation together with an assumed function belonging to at least one of the three categories below. Thus, selection of genes for subsequent validation was based on predefined categories and on the results from microarrays but was not done before the experiments. Predefined categories included "smooth muscle contraction," "growth," and "metabolism." Categorization to "smooth muscle contraction" was based on the assumption that smooth muscle contraction depends on a panel of functions including actin and extracellular matrix organization, adhesion (of the 
cytoskeleton to membranes and of cells to extracellular matrix), neurotransmitter release, and myosin light chain phosphorylation and on a panel of signaling pathways including $G$ protein-coupled receptors, heterotrimeric $G$ proteins, small monomeric GTPases, RhoA/Rho kinase, calcium, nitric oxide, and others [1]. Categorization to "growth" was based on a function in proliferation, survival, regulation of cell cycle, or differentiation. Searches for information of gene functions and gene ontology was performed using different data bases, including https://omim.org, https://genecards.org, and https://geneontology.org.

2.3. Human Prostate Tissues. Human prostate tissues were obtained from patients who underwent radical prostatectomy for prostate cancer $(n=44)$ as previously described [1]. This study was carried out in accordance with the Declaration of Helsinki of the World Medical Association and has been approved by the ethics committee of the LudwigMaximilians University, Munich, Germany. Informed consent was obtained from all patients. All samples and data were collected and analyzed anonymously. Patients with previous ablative surgery of the prostate were excluded. Tissues were taken solely from the periurethral zone, considering that most prostate cancers arise in the peripheral zone $[14,15]$. Prostates showing tumors in the periurethral zone upon macroscopic inspection (found in less than $1 \%$ of prostates undergoing this sampling procedure) were not subjected to sampling. $\mathrm{BPH}$ is present in ca. $80 \%$ of patients with prostate cancer $[16,17]$.

2.4. Real-Time Polymerase Chain Reaction (RT-PCR). RNA isolation from frozen prostate tissues or from cells and RTPCR were performed as previously described using primers provided by Qiagen (Hilden, Germany) [18]. Results were expressed using the $\Delta \Delta \mathrm{CP}$ method, where number of cycles (Ct) at which the fluorescence signal exceeded a defined threshold for GAPDH was subtracted from Ct values for target mRNAs $\left(\mathrm{Ct}_{\text {target }}-\mathrm{Ct}_{\mathrm{GAPDH}}=\Delta \mathrm{CP}\right)$, and values were calculated as $2^{-\triangle \mathrm{CP}}$. Correlation analyses were performed using the $2^{-\triangle \mathrm{CP}}$ values from concerning genes obtained from the same samples. In stimulation experiments performed in WPMY-1 cells, values of stimulated samples were expressed as fold of the mean of control samples.

2.5. Tension Measurements. Smooth muscle contraction of human prostate strips was performed as previously described in tissue baths with four chambers (Danish Myotechnology, Aarhus, Denmark) [18]. Dimethylsulfoxid (DMSO) for controls, L-692,585, or MK0677 was added 30 min before contractions and was induced by electric field stimulation (EFS) or by $\alpha_{1}$-adrenoceptor agonists. In each experiment, tissue from the same prostate was allocated to all four channels, and DMSO or one of the GHSR agonists was added to two channels following determination of $\mathrm{KCl}$-induced contractions and subsequent washout. Only one curve was recorded with each sample. For calculation of agonistinduced contractions, tensions were expressed as \% of $\mathrm{KCl}-$ induced contractions, which were induced by addition of a $2 \mathrm{M} \mathrm{KCl}$ solution to obtain a final high molar $\mathrm{KCl}$ concentra- tion of $80 \mathrm{mM}$. All samples (19 tissues, 4 samples per tissue) contracted in response to high molar $\mathrm{KCl}$, resulting in maximum KCl-induced contractions of $52.6 \pm 46.8 \mathrm{mN}$ (mean \pm standard deviation). $E_{\max }$ and $\mathrm{EC}_{50}$ values were calculated by curve fitting for each single experiment using GraphPad Prism 6 (Statcon, Witzenhausen, Germany) and analyzed as described below.

2.6. Culture and Stimulation of WPMY-1 Cells. WPMY-1 cells were obtained from American Type Culture Collection (ATCC; Manassas, VA, USA) and cultured, stimulated, and processed as previously described [18].

2.7. Plate Colony Assay. About 100 cells were placed to each well of a 6-well culture plate and treated with MK0677 in indicated concentrations. Cells were incubated at $37^{\circ} \mathrm{C}$ for 14 days, washed twice with phosphate-buffered saline (PBS), and fixed by $2 \mathrm{ml}$ of $10 \%$ trichloroacetic acid (TCA) overnight $\left(4^{\circ} \mathrm{C}\right)$. Subsequently, all plates were washed five times with cold water and stained with $0.4 \%$ sulforhodamine $\mathrm{B}$ (SRB) solution (diluted in $1 \%$ acetic acid) at room temperature for 30 minutes. Before taking photos for counting and documentation of representative wells, all plates were labelled and washed five times with $1 \%$ acetic acid. The number of all colonies (with a size of $1 \mathrm{~mm}$ ore more) was counted manually with assistance from Image from pictures taken from whole wells. Colonies growing close to each other and merging with each other were counted as one colony.

2.8. Flow Cytometry. For detection of cell cycle phase distribution by flow cytometry, WPMY-1 cells $\left(10^{5}\right.$ cells/well $)$ were grown overnight in 6-well plates. Subsequently, the medium was replaced by a serum-free medium, and cells were preincubated with and without MK-0677 (100 nM). After $24 \mathrm{~h}$ or $48 \mathrm{~h}$, preincubation media were removed; cells were rinsed with PBS for harvesting, fixed with ethanol, and centrifuged ( $500 \mathrm{~g}, 5 \mathrm{~min}$ ). Pellets were suspended in $1 \mathrm{ml}$ of precooled PBS for $1 \mathrm{~min}$, centrifuged ( $500 \mathrm{~g}, 5 \mathrm{~min}$ ), and suspended in $200 \mu \mathrm{l}$ RNase staining solution containing propidium iodide (PI) (Abcam, Cambridge, UK), which was added to each individual tube. Fluorescence was measured by flow cytometry using a FACSCalibur (Beckton Dicksinson, Franklin Lake, NJ, USA). Suitable forward scatter (FSC) vs. side scatter (SSC) was established to exclude debris and cell aggregates, and PI fluorescence signals in the FL2 channel using $488 \mathrm{~nm}$ laser illumination were collected. For each tube, the third-party Mod Fit LTTM software (Verity Software House, Torpsham, ME, USA) was used for data acquisition $\left(1 \times 10^{4}\right.$ events for each sample) and for analysis. Markers were set up on a histogram plot to delineate $<2 \mathrm{~N}, 2 \mathrm{~N}$ (G1 stage), 2N-4N (DNA synthesis), $4 \mathrm{~N}$ (mitotic), and $>4 \mathrm{~N}$ intensity regions. Results were expressed as \% of cells in different phases.

2.9. EdU Assay. 5-Ethynyl-2' -deoxyuridine (EdU) assay in MK0677- or solvent-stimulated WPMY-1 cells was performed as previously described using the "EdU-Click 555" cell proliferation assay (Baseclick, Tutzing, Germany) [18]. Results were expressed as \% of proliferating cells from the whole examined population. 
2.10. CCK-8 Assay. Viability of MK0677 in WPMY-1 cells was assessed as previously described using the cell counting kit 8 (CCK-8) (Sigma-Aldrich, St. Louis, MO, USA) [18]. Results were expressed as means of the optical density from all independent experiments.

2.11. Data and Statistical Analysis. Data are presented as means \pm standard deviation (SD) with the indicated number $(n)$ of independent experiments. Wherever this was feasible, all single values from all independent experiments or all samples are shown together with means. Statistical analyses were performed by nonparametric tests, with the exception for group comparisons in frequency and concentration response curves, where a Gaussian distribution may be assumed (2-way ANOVA). For comparison of paired groups from datasets containing two groups, the Wilcoxon Rank Sum test was applied. For comparison of datasets containing three related, correlating groups, the Friedman test was used. If the test was significant, a nonparametric post hoc test (Stepwise Stepdown Multiple Comparisons) was used for multiple comparisons, i.e., to locate which pairs are different. For comparison of datasets containing three unrelated, unpaired (i.e., independent) groups, 1-way ANOVA was applied. If the test was significant, Fisher's Least Significant Difference (LSD) test was used for multiple comparisons, i.e., to compare two groups within the dataset of three groups. All tests were performed using SPSS ${ }^{\circledR}$ version 20 (IBM SPSS Statistics, IBM Corporation, Armonk, New York, USA). $p$ values $<0.05$ were considered statistically significant. The present study and analyses were designed to be exploratory, but not designed to test a prespecified statistical null hypothesis. Therefore, $p$ values reported here should be considered as descriptive and not as hypothesis testing. All groups included in the statistical analyses were based on five or more independent experiments, so that minimum group size subjected to statistical tests was $n=5$, and all groups being compared with each other by statistical tests showed identical group sizes. In fact, despite the explorative design, the preplanned group sizes were $n=5$ for cell culture experiments, and $n=5$ or higher for other experiments, if the application of statistical analysis for descriptive $p$ values was intended. Microarray analyses were based on group sizes of $n=3$, so that no statistical tests were applied to these data. Series of organ bath experiments were finished as soon as meaningful results (with a descriptive $p$ value $<0.05$ ) were obtained with group sizes of $n=5$ or more, according to previous recommendations $[19,20]$. Considering validation of microarrayidentified genes in human prostate tissues, the sample size of 12 was chosen for technical reasons, together with the availability of prostate tissues. No data or experiments were excluded from analyses. Spearman's correlation analysis was performed using GraphPad Prism 6 (Statcon, Witzenhausen, Germany). No correlation analyses were performed but not reported, e.g., because correlations lacked statistical significance.

2.12. Materials, Drugs, and Nomenclature. MK0677 (2amino-N-[(1R)-2-[1,2-dihydro-1-(methylsulfonyl)spiro[3Hindole-3, $4^{\prime}$-piperidin $]-1^{\prime}$-yl]-2-oxo-1-[(phenylmethoxy)- methyl]ethyl]-2-methylpropanamide methanesulfonate) and L-692,585 (3-[[(2R)-2-hydroxypropyl]amino]-3methyl-N-[(3R)-2,3,4,5-tetrahydro-2-oxo-1-[[2' - $11 \mathrm{H}$-tetrazol-5-yl)[1,1'-biphenyl]-4-yl]methyl]-1H-1-benzazepin-3yl]-butanamide) are nonpeptide ghrelin receptor agonists. Stock solutions were prepared in DMSO and stored at $-20^{\circ} \mathrm{C}$ until used. Aqueous stock solutions of noradrenaline and the $\alpha_{1}$-adrenoceptor agonist phenylephrine were freshly prepared before each experiment. MK0677 and L692,858 were obtained from Tocris (Bristol, UK), and noradrenaline and phenylephrine were obtained from Sigma-Aldrich (Munich, Germany).

\section{Results}

3.1. Effects of Ghrelin on Prostate Size. BPH and prostate enlargement in rats can be induced by castration and subsequent testosterone supplementation (four weeks), which was aggravated by application of ghrelin (Figure 1(a)). Two weeks after oral ghrelin or vehicle treatment, body weights in ghrelin-treated BPH rats were higher compared to the vehicle group ( $365 \pm 40 \mathrm{~g}$ vs. $320 \pm 37 \mathrm{~g}$ ). This was paralleled by increased prostate wet weight $(1.03 \pm 0.096 \mathrm{~g}$ vs. $0.81 \pm$ $0.086 \mathrm{~g}$ ) and higher prostate body weight ratio in the ghrelin group compared to the vehicle group $\left(2.85 \pm 0.31 \times 10^{-3}\right.$ vs. $2.54 \pm 0.24 \times 10^{-3}$ ) (Figure 1(b)).

3.2. Effects of Ghrelin on Gene Expression in Rat Prostates. By microarray, we analyzed the effects of ghrelin on gene expression in prostates of rats with testosterone-induced BPH. The expression of 893 mRNAs was altered by ghrelin. $258 \mathrm{mRNAs}$ represent genes, which were upregulated 1-fold or more by ghrelin (i.e., showing values 2fold of controls). From these genes being upregulated at least 1-fold by ghrelin, 68 are genes for which a regulation of growth may be assumed, 15 are genes for which a role in regulation of smooth muscle contraction may be assumed, and 31 are genes for which a role in metabolism may be assumed (Figure 1(c)). 385 of the altered mRNAs represent genes, which were downregulated to 2 -fold or less by ghrelin. From these genes being downregulated 1fold or more by ghrelin, 44 are genes for which a regulation of growth may be assumed, 43 are genes for which a role in the regulation of smooth muscle contraction may be assumed, and 35 are genes for which a role in metabolism may be assumed (Figure 1(c)). Remaining mRNAs were altered less than 2-fold, or a primary function in growth, proliferation, or metabolism was not assumed from research in databases (Figure 1(c)).

3.3. Correlation of Ghrelin-Regulated Genes with BPH and GHSR Expression in Human Prostates. Findings from microarray analyses of rat prostates were verified in human prostate tissues obtained from radical prostatectomy. In these tissues, we analyzed mRNA of twelve selected genes from all three categories, which were identified by microarray (Table 1) together with mRNA for GHSR and prostatespecific antigen (PSA), which increases with degree of BPH $[18,21]$. Selected genes of the category "smooth muscle 


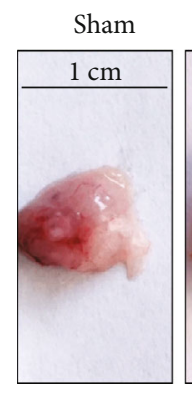

$\mathrm{BPH}$

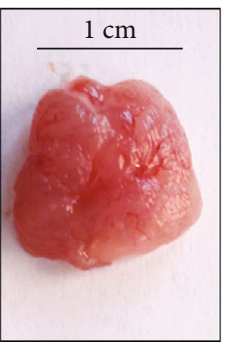

(a)
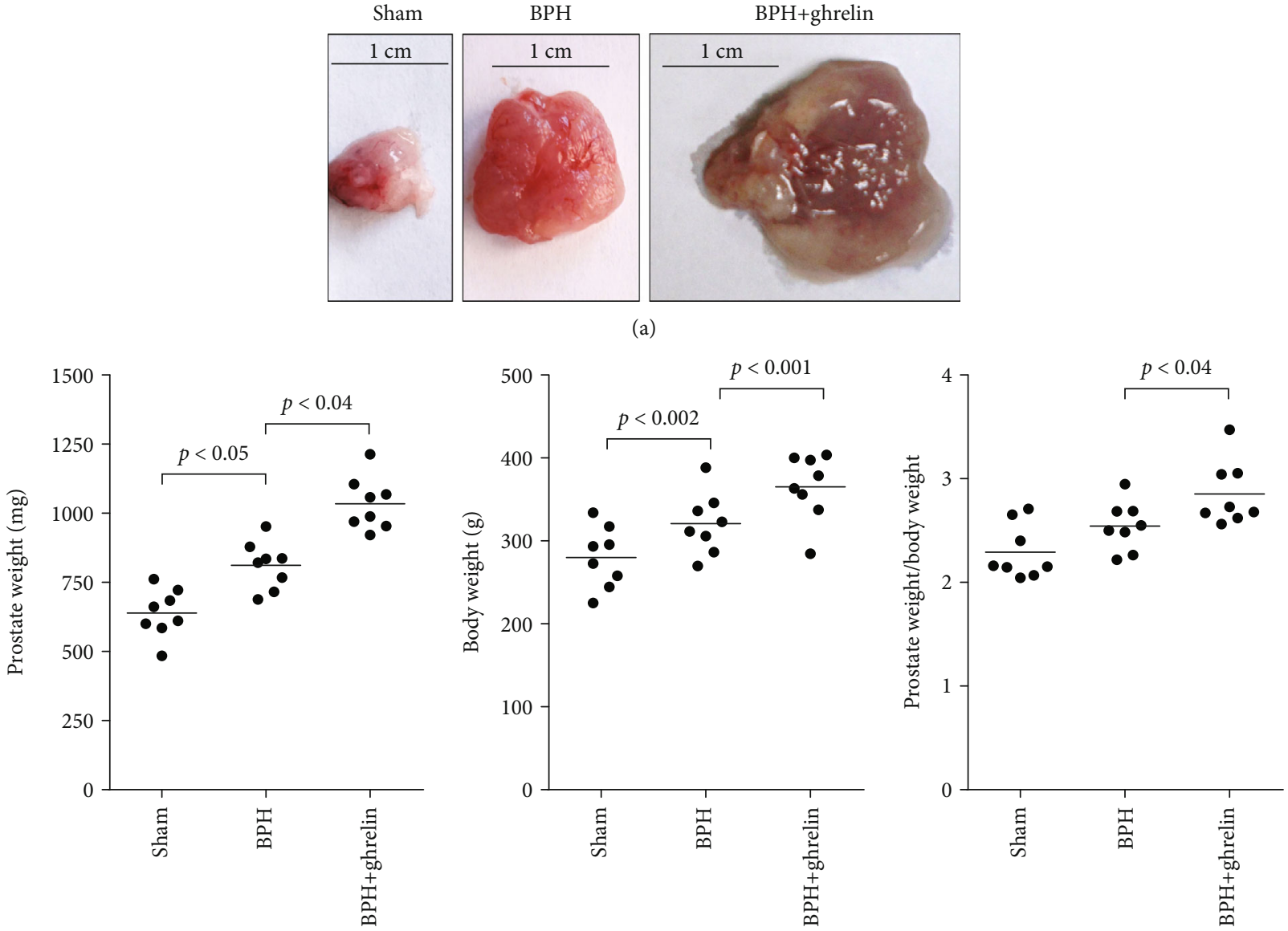

(b)

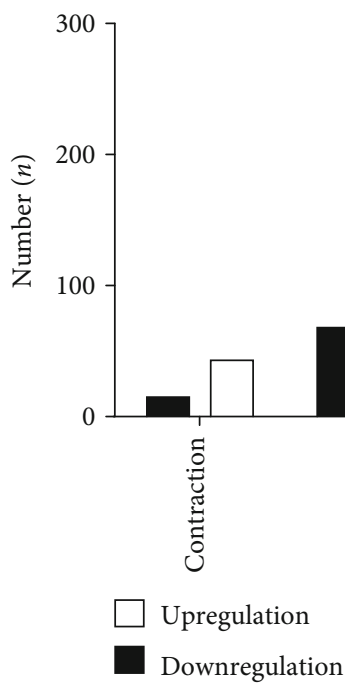

(c)

FIgURE 1: Ghrelin-induced regulation of prostate size and gene expression in rats with testosterone-induced BPH. (a) Testosterone supplementation $(3 \mathrm{mg} / \mathrm{kg}$ b.w., s.c., daily) for four weeks induces prostate enlargement in rats (compare sham with BPH), which was aggravated by ghrelin $(10 \mu \mathrm{g} / \mathrm{kg}$ body weight, i.p., $14 \mathrm{~d})$ (representative images, $n=8 \mathrm{rats} /$ group). (b) Prostate weight, body weight, and the ratio of prostate and body weight in sham-treated, BPH, and ghrelin-treated BPH rats. Shown are data of all rats from a series including $n=8$ rats/group and descriptive $p$ values (Friedman two-way ANOVA by ranks). (c) Numbers and functions of ghrelinregulated genes in prostates from rats with testosterone-induced $\mathrm{BPH}$, identified by microarray analysis $(n=3$ rats per group, i.e., $\mathrm{BPH}$ rats treated with ghrelin or vehicle). Putative function of genes, which were up- or downregulated 1-fold or more by ghrelin, was checked by research in databases. Subsequently, genes were sorted to indicated categories. 
TABLE 1: Ghrelin-upregulated genes in hyperplastic rat prostates, selected from microarray for further analysis in human prostate tissues and in WPMY-1 cells, grouped to functional categories. Rats with testosterone-induced BPH were treated with ghrelin (20 nmol/kg, daily) or vehicle. Prostates were harvested four weeks after initiation of ghrelin treatment and subjected to microarray analysis (prostates from $n=3$ animals per group). The selection represents genes, which were upregulated 1-fold or more by ghrelin treatment (fold change) and for which a function for growth, smooth muscle contraction, or metabolism appears likely.

\begin{tabular}{|c|c|c|}
\hline Gene & Fold change & Simplified description \\
\hline \multicolumn{3}{|l|}{ Growth } \\
\hline BMP6 & 8.764 & TGF-beta receptor agonist \\
\hline TTK & 4.258 & Proliferation-promoting kinase \\
\hline CCNE1 & 4.187 & Cyclin E1 \\
\hline FOXM1 & 2.649 & Transcriptional activator involved in proliferation \\
\hline \multicolumn{3}{|l|}{ Contraction } \\
\hline GAL & 10.13 & Regulation of neurotransmission \\
\hline SPON1 & 3.111 & ECM, adhesion, vascular smooth muscle \\
\hline LIMK2 & 2.432 & Smooth muscle contraction in hyperplastic human prostate \\
\hline RTKN2 & 2.418 & Rhotekin 2, effector of contraction-mediating Rho kinase \\
\hline ARHGEF4 & 2.267 & Rho guanine nucleotide exchange factor \\
\hline ABRA & 2.049 & Actin-binding Rho activating protein \\
\hline \multicolumn{3}{|l|}{ Metabolism } \\
\hline SLC10A6 & 5.006 & Metabolism, sugar import into cell \\
\hline THEM5 & 4.300 & Metabolism, lipid regulation \\
\hline
\end{tabular}

contraction" may be associated with regulation of RhoA or monomeric GTPases in general (ARHGEF4, ABRA), contraction-mediating kinases (RTKN2, LIMK2), cytoskeleton organization $(A B R A)$, neurotransmission $(G A L)$, or adhesion and extracellular matrix (SPON1). Selected genes of the category "growth" may be involved in proliferation (TTK, CCNE1, and FOXM1) or may be a growth factor (BMP6). Double functions and categorization to "growth" in addition to "smooth muscle contraction" appear feasible for SPON1, which may be involved in the regulation of proliferation besides extracellular matrix formation. Identified genes of the category "metabolism" (SLC10A6, THEM5) may be involved in fat metabolism, sugar transport, or lipid regulation. For 11 of the 12 selected genes, mRNA levels correlated positively with GHSR mRNA in human prostate tissues $(R>0.5)$ (Table 2). Positive correlation with PSA was only suggested for two of these genes (Table 2). Consistently, no correlation was evident between GHSR and PSA mRNAs following detection by RT-PCR, neither for $\Delta \Delta \mathrm{CP}$ values nor for $-\log \Delta \Delta \mathrm{CP}$ values $(R=0.164$ for $\Delta \Delta \mathrm{CP}, R=0.151$ for $-\log \Delta \Delta \mathrm{CP})$ (Figure 2(a)). Plotting of $-\log \Delta \Delta \mathrm{CP}$ suggested two groups of samples, i.e., one with stable and high GHSR mRNA levels despite varying content of PSA mRNA and another with GHSR mRNA levels increasing with PSA mRNA (Figure 2(a)). The validity of variation of these values was confirmed by the low variation of $\mathrm{Ct}$ values for GAPDH, which was used as reference (Figure 2(b)).

3.4. MK0677-Induced Gene Expression in WPMY-1 Cells. Ghrelin-dependent regulation of selected genes identified by microarray analyses of rat prostates (Table 1) and showing correlation with GHSR expression in human prostates was
TABLE 2: Correlation analysis for mRNAs of genes selected from microarray analysis with mRNAs of GHSR and PSA, based on mRNA detection by RT-PCR in human prostate tissues (samples from 12 patients for each gene).

\begin{tabular}{lcc}
\hline Gene & \multicolumn{2}{c}{ Correlation coefficient } \\
& With GHSR & With PSA \\
\hline BMP6 & 0.965 & -0.124 \\
TTK & 0.999 & 0.913 \\
CCNE1 & 0.959 & 0.063 \\
FOXM1 & 0.987 & -0.016 \\
GAL & 0.903 & -0.389 \\
SPON1 & 0.324 & -0.044 \\
LIMK1 & 0.536 & 0.514 \\
RTKN2 & 0.826 & -0.369 \\
ARHGEF4 & 0.679 & 0.452 \\
ABRA & 0.995 & -0.252 \\
SLC10A6 & 0.997 & -0.25 \\
THEM5 & 0.992 & -0.209 \\
\hline
\end{tabular}

examined by RT-PCR in WPMY-1 cells. WPMY-1 is an immortalized cell line from human prostate stroma, which may express GHSR, and shows a smooth muscle cell-like phenotype including the expression of the smooth muscle marker calponin, but lacking cytokeratin expression [22, 23]. Stimulation with the GHSR agonist MK0677 induced upregulation (resulting in mRNA levels 1.1-fold or more of unstimulated controls) of 10 from 12 examined genes, including two of the category "growth" (BMP6, CCNE1), two of the category "metabolism" (SLC10, THEM5), and at least four of the category "smooth muscle contraction" 


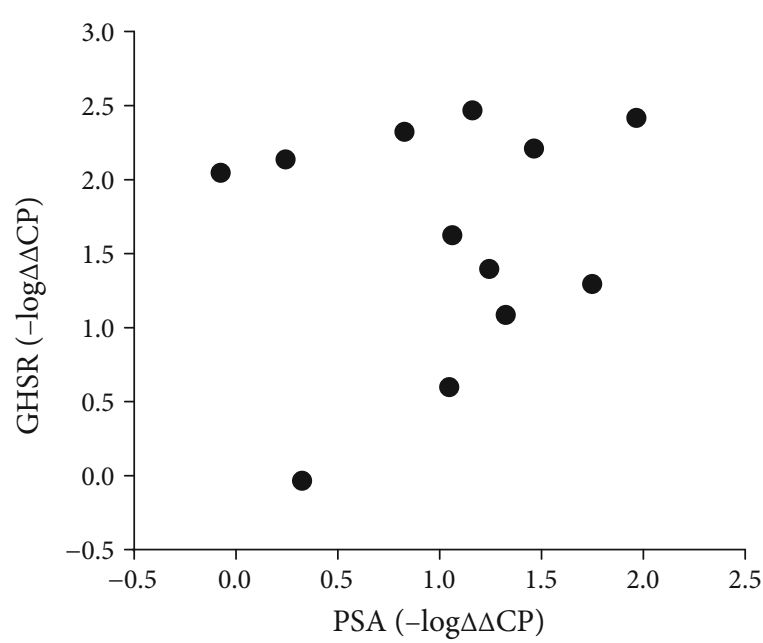

(a)

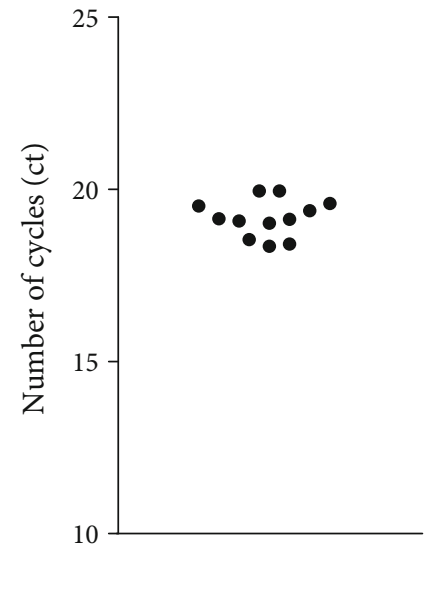

(b)

FIgURE 2: GHSR detection in human prostate tissue. (a) Correlation analysis for GHSR mRNA with PSA mRNA (-log $\Delta \Delta \mathrm{CP}$ ), following RT-PCR of human prostate tissues. (b) Ct values for GAPDH, single values from all prostates included to this analysis.

(GAL, SPON1, LIMK2, and ABRA) (Figure 3(a)). Similar results were obtained for $L I M K 1$, which was not selected based on microarray, but recently suggested to promote human prostate smooth muscle contraction (Figure 3(a)) [20]. Ct values for GAPDH, which was used for reference (housekeeping), were not changed by stimulation with MK0677 (average Ct $15.37 \pm 1.488$ in controls, $15.45 \pm$ 1.699 in MK0677-stimulated cells) (Figure 3(c)).

3.5. MK0677-Induced Proliferation of WPMY-1 Cells. Proliferation of WPMY-1 cells was assessed using several readouts (Figures 2 and 3). Stimulation with MK0677 $(100 \mathrm{nM}, 24 \mathrm{~h})$ increased the mRNA levels of three proliferation markers (Cdk4, cyclinD1, and Ki-67) (Figure 3(b)). Proliferation was confirmed by plate colony assay (Figure 4(a)) and EdU assay (Figure 4(b)), where MK0677 induced proliferation. Promotion of cell cycle was again demonstrated by flow cytometry, which suggested increased fractions of cells in the G2/M phase and decreased fractions of cells in the G1 phase following stimulation with MK0677 (Figure 5(a)). In line with the MK0677-induced proliferation, CCK-8 assays demonstrated that MK0677 does not induce cytotoxic effects but rather increases the viability of WPMY-1 cells (Figure 5(b)).

3.6. Effects of GHSR Agonists on Human Prostate Smooth Muscle Contraction. Effects of GHSR agonists on contractions of human prostate strips were assessed by myographic measurements. L-692,585 enhanced contractions induced by electric field stimulation, which are mediated by adrenergic neurotransmission (Figure 6(a)). This was confirmed by changed settings, where L-692,585 and MK0677 enhanced noradrenaline- and phenylephrine-induced contractions (Figures 6(b) and 6(c)). $E_{\max }$ values, which were calculated by curve fitting for each separate experiment and group (Figure 6), confirm the increases of EFS-, noradrenaline-, and phenylephrine-induced contractions by L-692,585 and MK0677 seen in concentration- and frequency-response curves. L-692,585 and MK0677 were without effects of $\mathrm{EC}_{50}$ values of noradrenaline and phenylephrine (Figure 6).

\section{Discussion}

Our findings demonstrate that GHSR activation promotes prostate growth and prostate smooth muscle contraction in $\mathrm{BPH}$, being imparted by genomic and nongenomic GHSR effects. Consequently, ghrelin may aggravate prostate enlargement, prostate smooth muscle tone, and finally urethral obstruction in patients with BPH. This may take place independent from the degree of $\mathrm{BPH}$, so that ghrelin may deteriorate hyperplastic growth and bladder outlet obstruction in addition to $\mathrm{BPH}$, e.g., in patients with $\mathrm{BPH}$ and metabolic syndrome. This may represent a mechanism explaining the association of metabolic syndrome with $\mathrm{BPH}$ and/or LUTS, which was previously evidenced by epidemiologic studies.

A main finding of our study is that treatment with ghrelin increased prostate size in rats with experimentally induced $\mathrm{BPH}$. In $\mathrm{BPH}$, prostate enlargement and increased prostate smooth muscle tone may both contribute to urethral compression and symptoms due to impaired bladder emptying [1]. By microarray, we identified genes, which were upregulated by ghrelin in prostates of rats with $\mathrm{BPH}$ and for which a role in smooth muscle contraction and proliferation may be assumed. We validated these findings (1) in cultured stromal cells, where expression of most of these genes was upregulated by GHSR activation, and (2) in human prostate tissues, where expression levels of most of these genes correlated with GHSR expression. Interestingly, a correlation with PSA expression or a correlation of GHSR expression with PSA content was not observed in human prostate tissues, leading to the conclusion that ghrelin actions may occur independently from the degree of $\mathrm{BPH}$ in the (hyperplastic) prostate. We assume that ghrelin may not necessarily cause $\mathrm{BPH}$ itself. Rather, our findings suggest that it may aggravate $\mathrm{BPH}$ and the factors underlying LUTS suggestive of $\mathrm{BPH}$. 


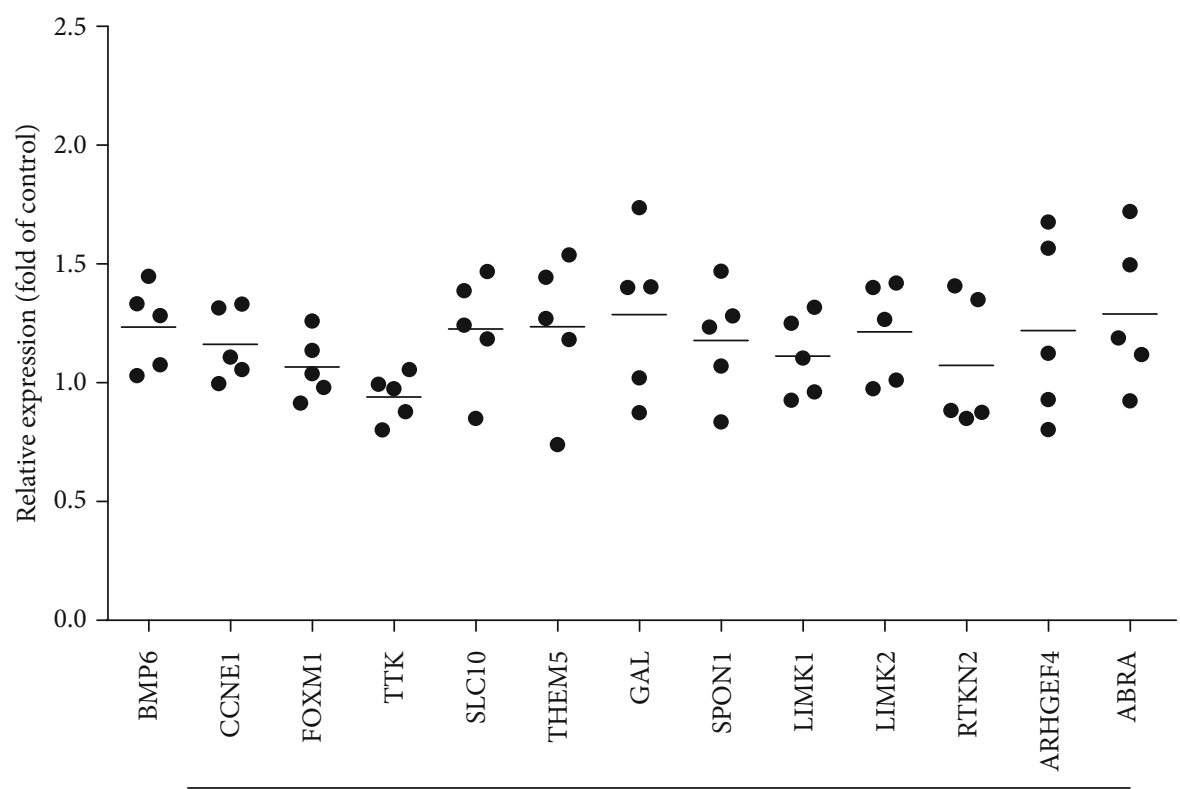

MK0677 (100 nM)

(a)

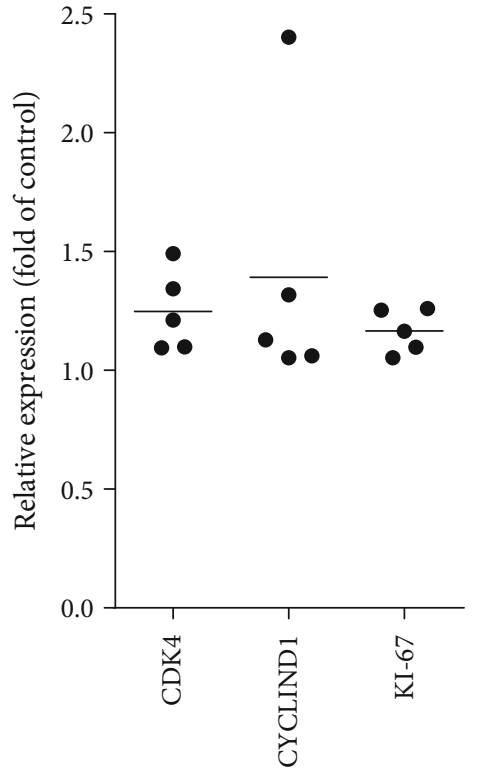

MK0677 (100 nM)

(b)

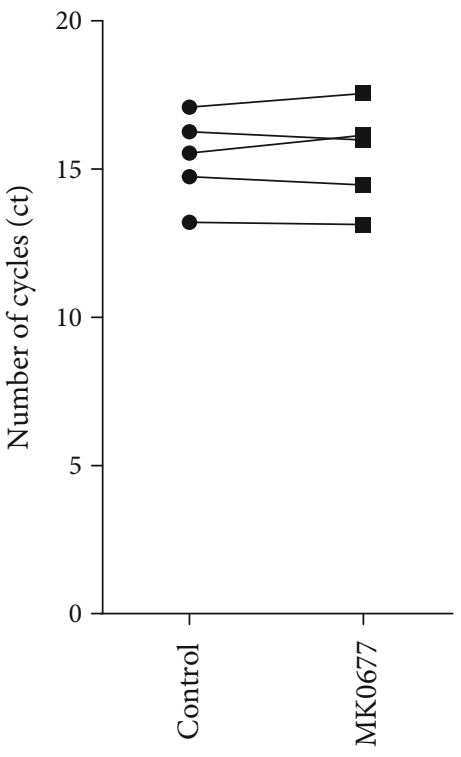

(c)

Figure 3: Effects of MK0677 on mRNA expression of selected genes in WPMY-1 cells. (a) Effects of MK0677 (24 h, $100 \mathrm{nM}$ ) on mRNA levels of genes selected from microarray in WPMY-1 cells, assessed by RT-PCR. Shown are relative expression levels compared to unstimulated controls (normalized to mean of controls, which is 1) (single values of stimulated samples, from each of five independent experiments, and mean for each gene as bar). (b) Effects of MK0677 (24h, $100 \mathrm{nM})$ on mRNA levels of proliferation markers in WPMY-1 cells, assessed by RT-PCR. Shown are relative expression levels compared to unstimulated controls (normalized to mean of controls, which is 1 ) (single values of stimulated samples, from each of five independent experiments, and mean for each gene as bar). (c) Ct values for GAPDH in cells with and without (control) stimulation with MK0677 (24h, $100 \mathrm{nM}$ ) (single values of samples from each of five independent experiments, with paired samples from each independent experiment connected by a line).

Thus, in patients with BPH, increased GHSR activity and/or metabolic syndrome may increase the risk for progression of $\mathrm{BPH}$. Finally, our data may point to two groups with different relationships between GHSR expression and BPH, although an overall correlation was not observed. Thus, an allocation to groups with stable, high GHSR expression despite varying PSA on the one hand and with a GHSR expression increasing with PSA on the other hand appears possible. Confirming 

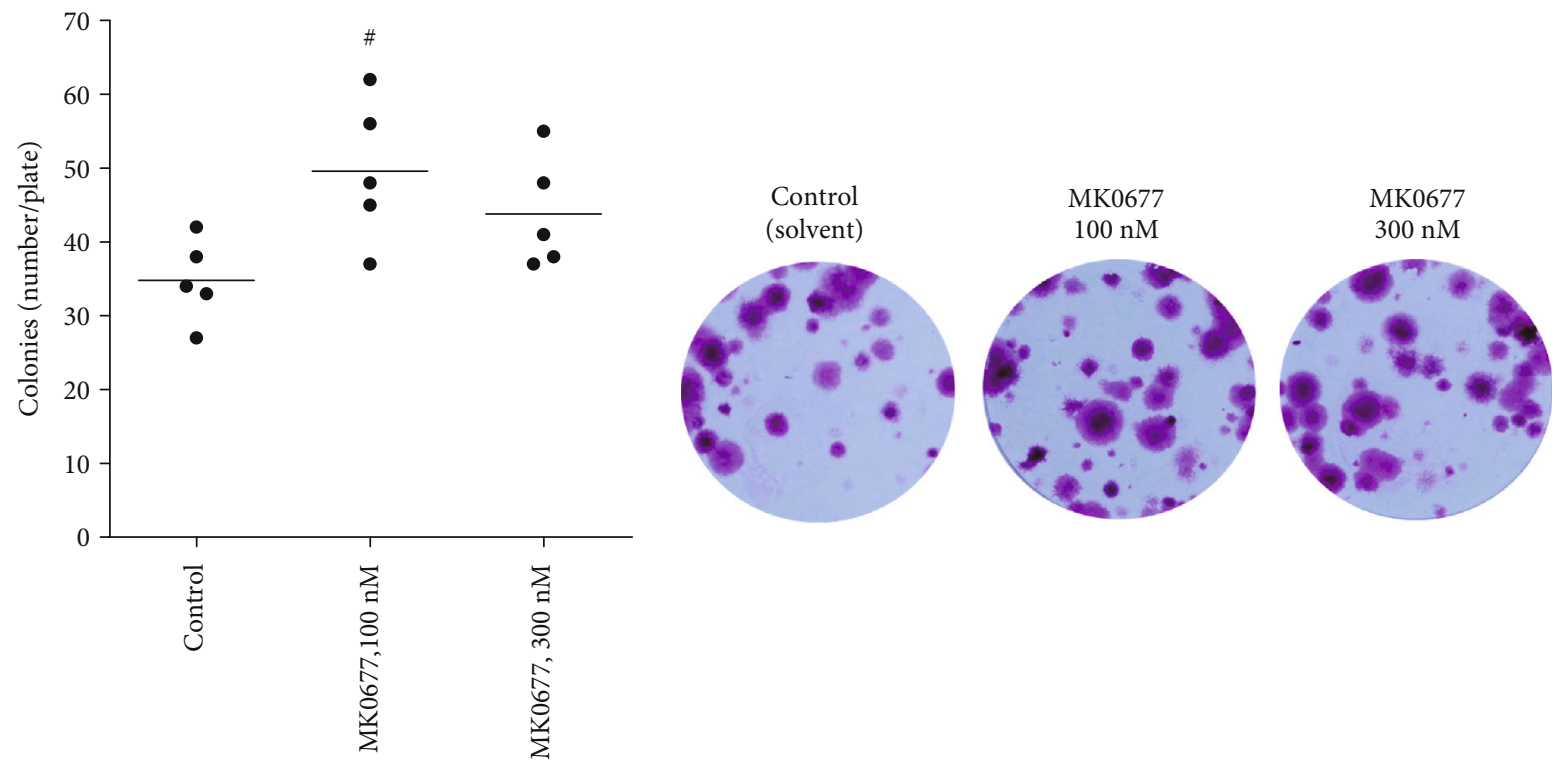

(a)
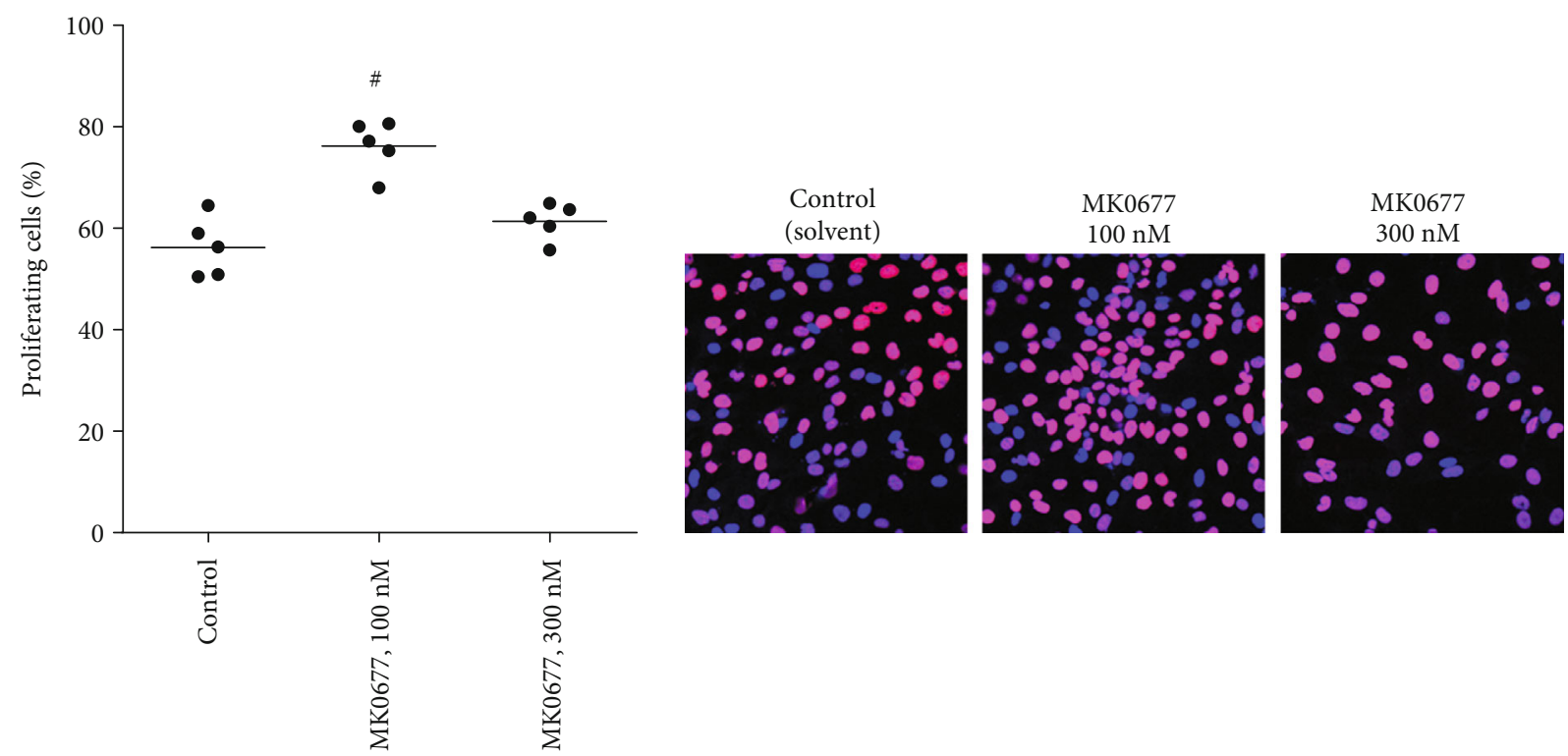

(b)

FIgURE 4: Effects of MK0677 on proliferation in WPMY-1 cells. (a) Effects of MK0677 (14 d) in plate colony assay (single values from each of five independent experiments, with mean for each gene as bar, and representative plates $)\left({ }^{\#} p<0.04\right.$ vs. control after Friedman two-way ANOVA by ranks). (b) Effects of MK0677 $(24 \mathrm{~h})$ on proliferation, assessed by EdU assay (single values from each of five independent experiments, with mean for each gene as bar, and representative images) $\left({ }^{\#} p<0.02\right.$ vs. control after Friedman two-way ANOVA by ranks).

and characterization of these relationships should be a subject of future studies and require higher sample sizes as in our explorative study.

Our findings suggest that GHSR activation may promote prostate smooth muscle contraction by genomic actions and nongenomic actions. Thus, ghrelin-induced upregulation of procontractile genes was paralleled by increases of smooth muscle contraction in the organ bath following short-time exposure of human prostate strips to GHSR agonists. It appears possible that both can take place in vivo, where increased prostate smooth muscle tone is a major factor contributing to urethral obstruction and LUTS suggestive of $\mathrm{BPH}[24,25]$. We observed similar results using different GHSR agonists (MK0677, L-692,585) and different $\alpha_{1}$-adrenoceptor agonists (phenylephrine, noradrenaline), so that these different settings may confirm each other. In the prostate, adrenergic neurotransmission causes smooth muscle contraction by activation of postsynaptic $\alpha_{1}$-adrenoceptors. Accordingly, neurogenic contractions induced by EFS were enhanced as well by L-692,585. It has previously been shown that MK0677 and L-692,585 may both activate phospholipase $\mathrm{C}$ followed by inositol1,4,5-trisphosphate production and may induce calcium mobilization [26-29]. Both processes mediate smooth 
G1 phase
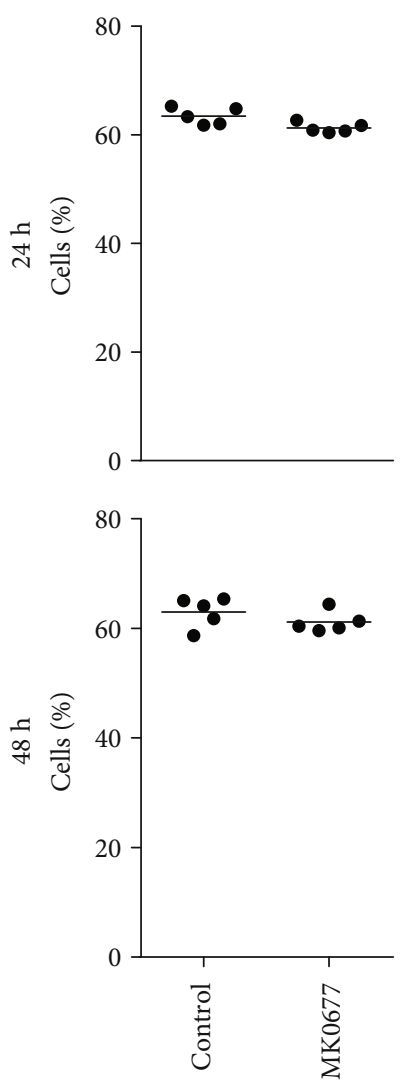

$24 \mathrm{~h}$

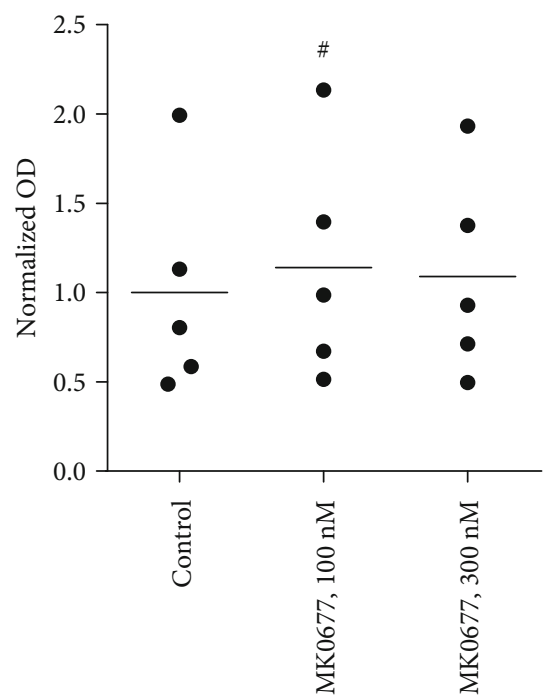

$S$ phase
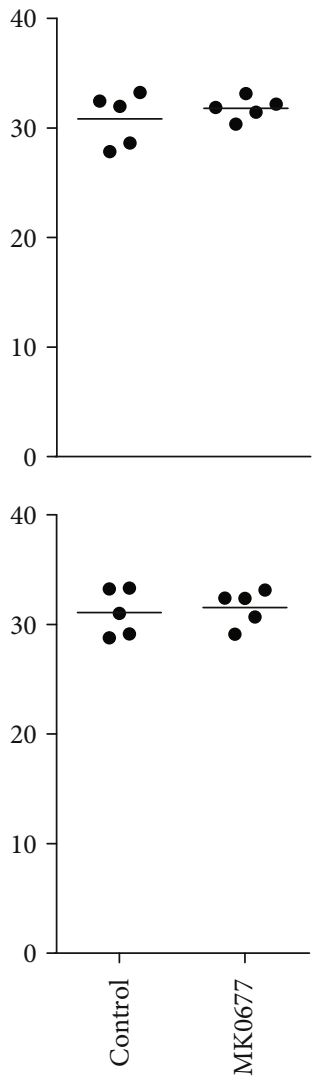

(a)
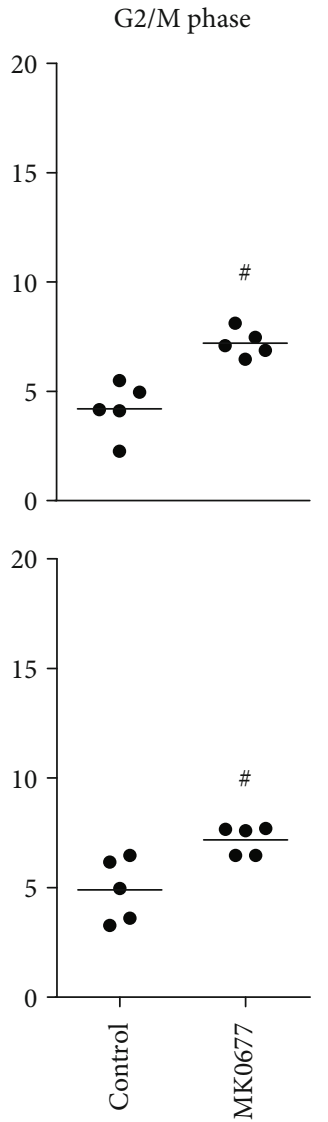

$48 \mathrm{~h}$

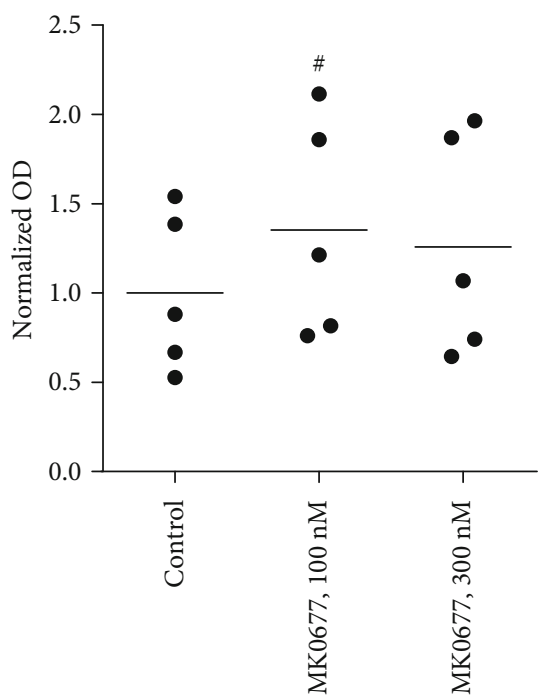

(b)

Figure 5: Effects of MK0677 on cell cycle and viability in WPMY-1 cells. (a) Effects of MK0677 (100 nM, 24-48 h) on cell cycle phases, assessed by flow cytometry analyses. Shown are representative experiments (left panels), and single values from each of five independent experiments, with mean for each gene as bar $\left({ }^{\#} p<0.05\right.$ vs. control after Wilcoxon Rank Sum test). In figures for representative experiments, the G1 phase is represented by the first red peak, the G2/M phase by the second red peak, and the S phase by the hatched areas. (b) Effects of MK0677 on viability, assessed by CCK-8 assays (single values from each of five independent experiments, with mean for each gene as bar) ( $p<0.04$ vs. control after Friedman two-way ANOVA by ranks). 


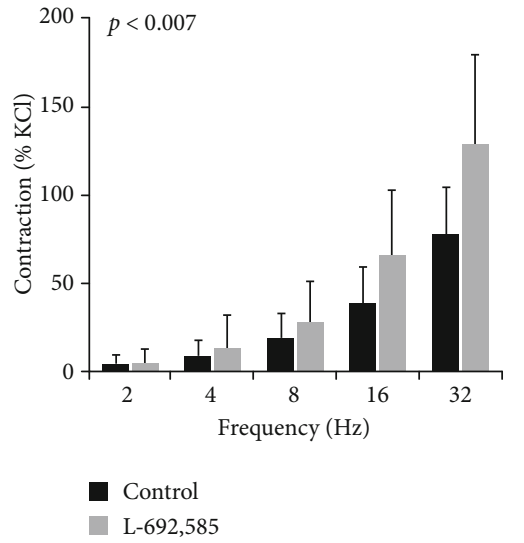

(A)

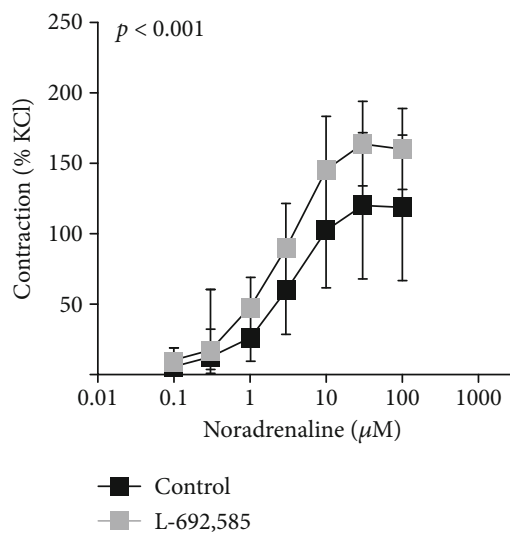

(A)

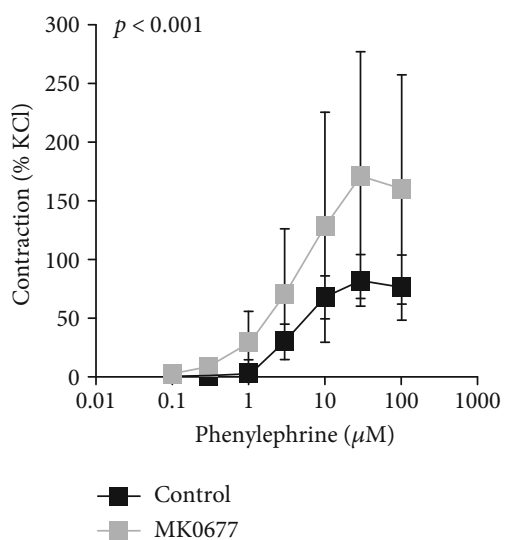

(A)

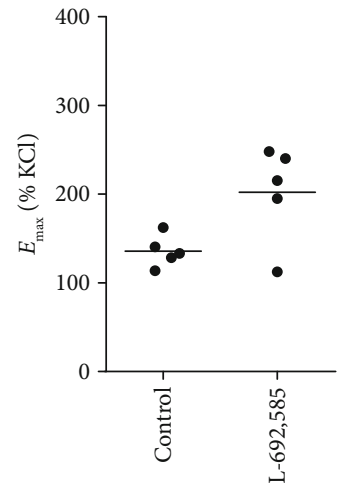

(B)

(a)

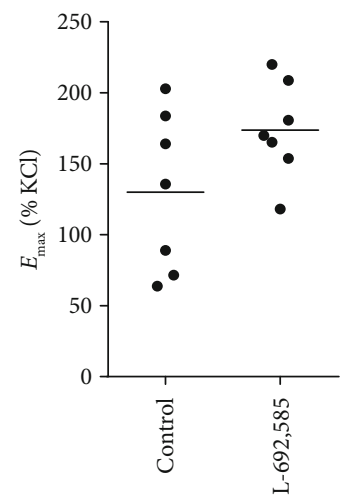

(B)

(b)

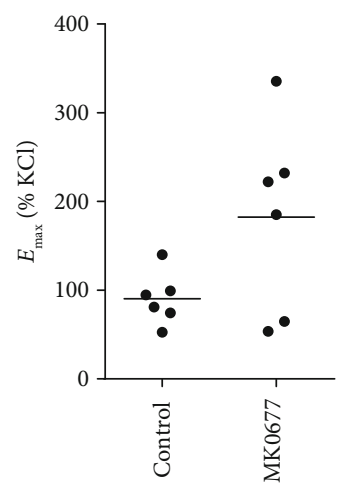

(B)

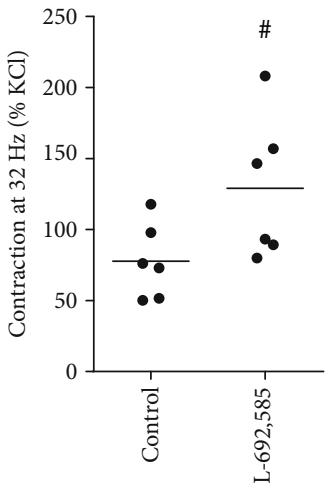

(C)

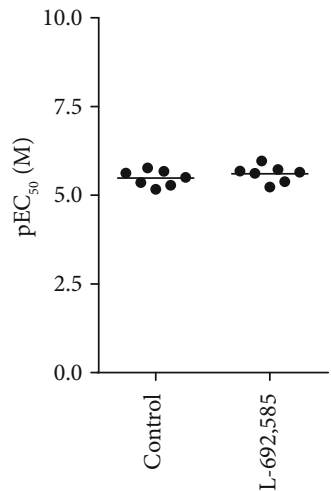

(C)

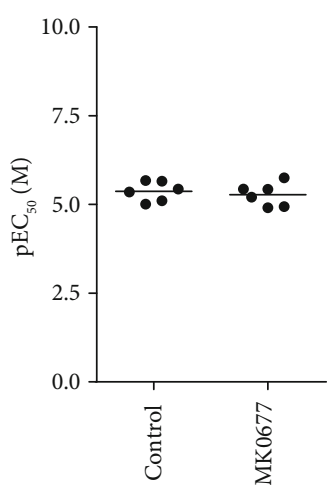

(C)

(c)

Figure 6: Effects of GHSR agonists on contractility of human prostate tissues. (a) Effects of L-692,585 (300 nM) on contractions of human prostate strips induced by electric field stimulation (tissues from $n=6$ patients). (b) Effects of L-692,585 (300 nM) on contractions of human prostate strips induced by noradrenaline (tissues from $n=7$ patients). (c) Effects of MK0677 (100 nM) on contractions of human prostate strips induced by the $\alpha_{1}$-adrenoceptor agonist phenylephrine (tissues from $n=6$ patients). In all series, tissue from each patient being allocated to control and GHSR agonist group in each experiment. Data are mean \pm SD in frequency- and concentration-response curves ( $p$ value from 2-way ANOVA for comparison between groups as indicated in frequency and concentration response curves) (A), $E_{\max }$ values for each single experiment (calculated by curve fitting) in (b) and (c) (B), and from 5 of 6 experiments in (a, B) (as feasible calculation was not possible for one experiment) $\left({ }^{\#} p<0.03\right.$ vs. control after Wilcoxon Rank Sum test), single values for 32 hertz-induced contractions in (a, C), and $\mathrm{pEC}_{50}$ values for each single experiment (calculated by curve fitting) in (b) and (c) (C). 
muscle contraction in the prostate [1]. Consequently, it appears possible that MK0677 and L-692,585 promoted $\alpha_{1}$-adrenergic contractions of prostate strips by these pathways.

In WPMY-1 cells, MK0677-induced proliferation was confirmed by different readouts. Ghrelin-mediated proliferation has been well-documented for different cell types $[6,7]$. Regarding smooth muscle cells outside the prostate, effects of ghrelin on proliferation and cell cycle have been reported for vascular smooth muscle cells, although with conflicting results. Several studies pointed to an inhibition of proliferation by ghrelin in vascular smooth muscle cells, which may oppose our findings in WPMY-1 cells [30-32]. Other findings may suggest the opposite, as ghrelin inhibited apoptosis of vascular smooth muscle cells, and mice with GHSR deficiency showed reduced numbers of smooth muscle cells in the neointima of arteries with wire-induced injury [31, 33]. Together, our data suggest that ghrelin promotes growth of prostate cells, which is supported by cell culture experiments and in vivo using a rat model with experimentally induced $\mathrm{BPH}$.

Our findings in isolated tissues and cell culture were obtained using small molecule GHSR agonists. MK0677 and L-692,585 were developed as orally available, potent growth hormone secretagogues. Both compounds resulted from optimization of preceding lead compounds to induce growth hormone release in rat pituitary cell assays, where MK0677 showed an $\mathrm{EC}_{50}$ of $1.3 \mathrm{nM}$ and L-692,585 of $3 \mathrm{nM}[34,35]$. Oral availability of MK0677 and L-692,585 was first confirmed in dog models [36-38]. Following the discovery of the GHSR, both compounds were identified as agonists of this receptor. MK0677 activates GHSRcoupled pathways and induces GHSR-mediated effects with $\mathrm{EC}_{50}$ values in the nanomolar range $(0.2-1.4 \mathrm{nM})$ [27]. In contrast to their efficacies in the nanomolar range, receptor binding may differ between MK0677 and L-692,585. MK0677 was identified as a competitive receptor agonist, while L-692,585 may act by mixed mechanisms including a strong allosteric component of action [27, 28]. Thus, Ki values of $6.5 \mathrm{nM}$ for MK0677, but of $2.5 \mu \mathrm{M}$ for $\mathrm{L}$ 692,585 , were reported from ghrelin competition assay [27, 28]. GHSR binding of MK0677 and activation of receptor-coupled signaling pathways have been intensively studied. With regard to receptor binding, affinity, potency, and signaling activation, MK0677 strongly resembles endogenous acyl-ghrelin, probably much more than other nonpeptide GHSR agonists do [27, 39, 40]. Obviously, GHSR1a is currently the only known target for MK0677. In fact, MK0677 does not bind the splice variant GHSR1b [41]. On the other hand, binding to other G proteincoupled receptors has to the best of our knowledge not been examined. However, as MK0677 activates the GHSR with a very similar behaviour than ghrelin peptides, most of its effects may be mediated by this receptor.

Considering our findings suggesting aggravation of prostate growth, stromal cell proliferation, and smooth muscle contraction by ghrelin, it appears possible that patients with $\mathrm{BPH} / \mathrm{LUTS}$ may profit from ghrelin management. The tolerability of several small molecule GHSR ligands has been con- firmed in clinical studies [6]. Most promising may be inverse agonists, as the efficacy of pure antagonists is limited by high intrinsic GHSR activity $[6,42,43]$. It may be anticipated that GHSR antagonism (or inverse agonism, respectively) reduces prostate enlargement and smooth muscle tone simultaneously, so that clinical studies with inverse agonists may be attractive in patients with LUTS suggestive of BPH. Cardiovascular side effects of $\alpha_{1}$-blockers resulting from vasorelaxation often limit medical therapy and may account for discontinuation rates up to $65 \% 12$ months after first prescription $[2,44]$. Ghrelin peptides or GHSR agonists do not show hemodynamic effects or induce hypotension, so that adverse events similar to those of $\alpha_{1}$-blockers may not be expected from inverse GHSR antagonists [45-47]. Currently, combination therapies with $5 \alpha$-reductase inhibitors and $\alpha_{1}$ blockers are required to address prostate enlargement and symptoms at once [2]. From GHSR antagonists or inverse agonists, both may be expected at once. Novel medications are of high demand, considering the insufficient efficacy of current options, high discontinuation rates, and the foreseeable rise in patients' numbers. The ghrelin system and other metabolic hormones merit further consideration in the context of LUTS suggestive of BPH.

\section{Abbreviations}

$\mathrm{BPH}$ : Benign prostatic hyperplasia

LUTS: Lower urinary tract symptoms

GHSR: Growth hormone secretagogue receptor

TURP: Transurethral resection of the prostate

PSA: Prostate-specific antigen

EFS: $\quad$ Electric field stimulation

FACS: Fluorescence-activated cell sorting

FSC: Forward scatter

SSC: $\quad$ Side scatter

PI: $\quad$ Propidium iodide

EdU: 5-Ethynyl-2' -deoxyuridine

CCK-8: Cell counting kit 8

SRB: Sulforhodamine B

GTP: Guanosine- $5^{\prime}$-triphosphate

GEO: Gene expression omnibus.

\section{Data Availability}

All data used to support the findings of this study are included within the article.

\section{Conflicts of Interest}

The authors have no conflict of interests to declare.

\section{Authors' Contributions}

Xiaolong Wang and Yiming Wang contributed equally to this work. 


\section{Acknowledgments}

We thank Prof. Dr. E. Noessner and her coworkers (Institute of Molecular Immunology, Helmholtz Center, Munich) for their support with immunofluorescence microscopy and Prof. Dr. T. Kirchner (Institute of Pathology, LudwigMaximilians University, Munich) and his coworkers for the acervation of tissue samples from prostates. This work was supported by grants from the Deutsche Forschungsgemeinschaft (grants HE 5825/8-1 and GR 3333/8-1) and the Guangdong Natural Science Foundation of China (grant No. 2016A030310386).

\section{References}

[1] M. Hennenberg, C. G. Stief, and C. Gratzke, "Prostatic $\alpha 1-$ adrenoceptors: new concepts of function, regulation, and intracellular signaling," Neurourology and Urodynamics, vol. 33, no. 7, pp. 1074-1085, 2014.

[2] M. Oelke, A. Bachmann, A. Descazeaud et al., "EAU guidelines on the treatment and follow-up of non-neurogenic male lower urinary tract symptoms including benign prostatic obstruction," European Urology, vol. 64, no. 1, pp. 118-140, 2013.

[3] D. W. Strand, D. N. Costa, F. Francis, W. A. Ricke, and C. G. Roehrborn, "Targeting phenotypic heterogeneity in benign prostatic hyperplasia," Differentiation, vol. 96, pp. 49-61, 2017.

[4] P. Dahm, M. Brasure, R. MacDonald et al., "Comparative effectiveness of newer medications for lower urinary tract symptoms attributed to benign prostatic hyperplasia: a systematic review and meta-analysis," European Urology, vol. 71, no. 4, pp. 570-581, 2017.

[5] L. Vignozzi, M. Gacci, and M. Maggi, "Lower urinary tract symptoms, benign prostatic hyperplasia and metabolic syndrome," Nature Reviews Urology, vol. 13, no. 2, pp. 108-119, 2016.

[6] B. Callaghan and J. B. Furness, "Novel and conventional receptors for ghrelin, desacyl-ghrelin, and pharmacologically related compounds," Pharmacological Reviews, vol. 66, no. 4, pp. 9841001, 2014.

[7] G. Collden, M. H. Tschop, and T. D. Muller, "Therapeutic potential of targeting the ghrelin pathway," International Journal of Molecular Sciences, vol. 18, no. 4, p. 798, 2017.

[8] S. AlSaif, S. Mumtaz, and S. Wray, "A short review of adipokines, smooth muscle and uterine contractility," Life Sciences, vol. 125, pp. 2-8, 2015.

[9] D. Z. Dimitrova, D. N. Mihov, R. Wang et al., "Contractile effect of ghrelin on isolated guinea-pig renal arteries," Vascular Pharmacology, vol. 47, no. 1, pp. 31-40, 2007.

[10] R. Barazzoni, M. Zanetti, C. Ferreira et al., "Relationships between desacylated and acylated ghrelin and insulin sensitivity in the metabolic syndrome," The Journal of Clinical Endocrinology and Metabolism, vol. 92, no. 10, pp. 3935-3940, 2007.

[11] L. M. Seoane, S. Tovar, R. Baldelli et al., "Ghrelin elicits a marked stimulatory effect on GH secretion in freely-moving rats," European Journal of Endocrinology, vol. 143, no. 5, pp. R7-R9, 2000.

[12] P. Ceranowicz, Z. Warzecha, A. Dembinski et al., "Treatment with ghrelin accelerates the healing of acetic acid-induced gastric and duodenal ulcers in rats," Journal of Physiology and Pharmacology, vol. 60, no. 1, pp. 87-98, 2009.
[13] D. Maduzia, A. Matuszyk, D. Ceranowicz et al., "The influence of pretreatment with ghrelin on the development of aceticacid-induced colitis in rats," Journal of Physiology and Pharmacology, vol. 66, no. 6, pp. 875-885, 2015.

[14] W. Pradidarcheep, C. Wallner, N. F. Dabhoiwala, and W. H. Lamers, "Anatomy and histology of the lower urinary tract," Handbook of Experimental Pharmacology, vol. 202, pp. 117148, 2011.

[15] Z. Shaikhibrahim, A. Lindstrot, J. Ellinger et al., "The peripheral zone of the prostate is more prone to tumor development than the transitional zone: is the ETS family the key?," Molecular Medicine Reports, vol. 5, no. 2, pp. 313-316, 2012.

[16] A. Alcaraz, P. Hammerer, A. Tubaro, F. H. Schroder, and R. Castro, "Is there evidence of a relationship between benign prostatic hyperplasia and prostate cancer? Findings of a literature review," European Urology, vol. 55, no. 4, pp. 864-875, 2009.

[17] D. D. Orsted and S. E. Bojesen, "The link between benign prostatic hyperplasia and prostate cancer," Nature Reviews Urology, vol. 10, no. 1, pp. 49-54, 2013.

[18] Y. Wang, C. Gratzke, A. Tamalunas et al., "Smooth muscle contraction and growth of stromal cells in the human prostate are both inhibited by the src family kinase inhibitors, AZM475271 and PP2," British Journal of Pharmacology, vol. 173, no. 23, pp. 3342-3358, 2016.

[19] M. J. Curtis, R. A. Bond, D. Spina et al., "Experimental design and analysis and their reporting: new guidance for publication in BJP," British Journal of Pharmacology, vol. 172, no. 14, pp. 3461-3471, 2015.

[20] Q. Yu, C. Gratzke, Y. Wang et al., "Inhibition of human prostate smooth muscle contraction by the LIM kinase inhibitors, SR7826 and LIMKi3," British Journal of Pharmacology, vol. 175, no. 11, pp. 2077-2096, 2018.

[21] J. M. Levitt and K. M. Slawin, "Prostate-specific antigen and prostate-specific antigen derivatives as predictors of benign prostatic hyperplasia progression," Current Urology Reports, vol. 8, no. 4, pp. 269-274, 2007.

[22] M. M. Webber, N. Trakul, P. S. Thraves et al., "A human prostatic stromal myofibroblast cell line WPMY-1: a model for stromal-epithelial interactions in prostatic neoplasia," Carcinogenesis, vol. 20, no. 7, pp. 1185-1192, 1999.

[23] Y. Wang, C. Gratzke, A. Tamalunas et al., "P21-activated kinase inhibitors FRAX486 and IPA3: inhibition of prostate stromal cell growth and effects on smooth muscle contraction in the human prostate," PLoS One, vol. 11, no. 4, article e0153312, 2016.

[24] M. Caine, A. Pfau, and S. Perlberg, "The use of alphaadrenergic blockers in benign prostatic obstruction," British Journal of Urology, vol. 48, no. 4, pp. 255-263, 1976.

[25] M. Caine, S. Raz, and M. Zeigler, "Adrenergic and cholinergic receptors in the human prostate, prostatic capsule and bladder neck," British Journal of Urology, vol. 47, no. 2, pp. 193-202, 1975.

[26] A. Glavaski-Joksimovic, K. Jeftinija, A. Jeremic, L. L. Anderson, and S. Jeftinija, "Mechanism of action of the growth hormone secretagogue, L-692,585, on isolated porcine somatotropes," The Journal of Endocrinology, vol. 175, no. 3, pp. 625-636, 2002.

[27] B. Holst, E. Brandt, A. Bach, A. Heding, and T. W. Schwartz, "Nonpeptide and peptide growth hormone secretagogues act both as ghrelin receptor agonist and as positive or negative 
allosteric modulators of ghrelin signaling," Molecular Endocrinology, vol. 19, no. 9, pp. 2400-2411, 2005.

[28] K. A. Bennett, C. J. Langmead, A. Wise, and G. Milligan, "Growth hormone secretagogues and growth hormone releasing peptides act as orthosteric super-agonists but not allosteric regulators for activation of the $\mathrm{G}$ protein Galpha(o1) by the ghrelin receptor," Molecular Pharmacology, vol. 76, no. 4, pp. 802-811, 2009.

[29] B. Holst, A. Cygankiewicz, T. H. Jensen, M. Ankersen, and T. W. Schwartz, "High constitutive signaling of the ghrelin receptor-identification of a potent inverse agonist," Molecular Endocrinology, vol. 17, no. 11, pp. 2201-2210, 2003.

[30] F. Rossi, A. Castelli, M. J. Bianco, C. Bertone, M. Brama, and V. Santiemma, "Ghrelin inhibits contraction and proliferation of human aortic smooth muscle cells by cAMP/PKA pathway activation," Atherosclerosis, vol. 203, no. 1, pp. 97-104, 2009.

[31] M. Zhan, F. Yuan, H. Liu, H. Chen, X. Qiu, and W. Fang, "Inhibition of proliferation and apoptosis of vascular smooth muscle cells by ghrelin," Acta Biochimica et Biophysica Sinica, vol. 40, no. 9, pp. 769-776, 2008.

[32] M. Duran-Prado, M. Morell, V. Delgado-Maroto et al., "Cortistatin inhibits migration and proliferation of human vascular smooth muscle cells and decreases neointimal formation on carotid artery ligation," Circulation Research, vol. 112, no. 11, pp. 1444-1455, 2013.

[33] J. Li, M. Zhang, M. Wang et al., "GHSR deficiency suppresses neointimal formation in injured mouse arteries," Biochemical and Biophysical Research Communications, vol. 479, no. 2, pp. 125-131, 2016.

[34] A. A. Patchett, R. P. Nargund, J. R. Tata et al., "Design and biological activities of L-163,191 (MK-0677): a potent, orally active growth hormone secretagogue," Proceedings of the National Academy of Sciences of the United States of America, vol. 92, no. 15, pp. 7001-7005, 1995.

[35] W. R. Schoen, D. Ok, R. J. De Vita et al., "Structure-activity relationships in the amino acid sidechain of L-692,429," Bioorganic \& Medicinal Chemistry Letters, vol. 4, no. 9, pp. 11171122, 1994.

[36] T. Jacks, G. Hickey, F. Judith et al., "Effects of acute and repeated intravenous administration of L-692,585, a novel non-peptidyl growth hormone secretagogue, on plasma growth hormone, IGF-1, ACTH, cortisol, prolactin, insulin, and thyroxine levels in beagles," The Journal of Endocrinology, vol. 143, no. 2, pp. 399-406, 1994.

[37] T. Jacks, R. Smith, F. Judith et al., "MK-0677, a potent, novel, orally active growth hormone $(\mathrm{GH})$ secretagogue: $\mathrm{GH}$, insulin-like growth factor I, and other hormonal responses in beagles," Endocrinology, vol. 137, no. 12, pp. 5284-5289, 1996.

[38] R. G. Smith, S. S. Pong, G. Hickey et al., "Modulation of pulsatile GH release through a novel receptor in hypothalamus and pituitary gland," Recent Progress in Hormone Research, vol. 51, pp. 261-285, 1996.

[39] P. Cassoni, M. Papotti, C. Ghè et al., "Identification, characterization, and biological activity of specific receptors for natural (ghrelin) and synthetic growth hormone secretagogues and analogs in human breast carcinomas and cell lines," The Journal of Clinical Endocrinology \& Metabolism, vol. 86, no. 4, pp. 1738-1745, 2001.

[40] S. S. Pong, L. Y. Chaung, D. C. Dean, R. P. Nargund, A. A. Patchett, and R. G. Smith, "Identification of a new Gprotein-linked receptor for growth hormone secretagogues," Molecular Endocrinology, vol. 10, no. 1, pp. 57-61, 1996.
[41] R. G. Smith, O. C. Palyha, S. D. Feighner et al., "Growth hormone releasing substances: types and their receptors," Hormone Research in Paediatrics, vol. 51, Suppl 3, pp. 1-8, 1999.

[42] K. O. Cameron, S. K. Bhattacharya, and A. K. Loomis, "Small molecule ghrelin receptor inverse agonists and antagonists," Journal of Medicinal Chemistry, vol. 57, no. 21, pp. 86718691, 2014.

[43] W. S. Denney, G. E. Sonnenberg, S. Carvajal-Gonzalez, T. Tuthill, and V. M. Jackson, "Pharmacokinetics and pharmacodynamics of PF-05190457: the first oral ghrelin receptor inverse agonist to be profiled in healthy subjects," British Journal of Clinical Pharmacology, vol. 83, no. 2, pp. 326-338, 2017.

[44] L. Cindolo, L. Pirozzi, C. Fanizza et al., "Drug adherence and clinical outcomes for patients under pharmacological therapy for lower urinary tract symptoms related to benign prostatic hyperplasia: population-based cohort study," European Urology, vol. 68, no. 3, pp. 418-425, 2015.

[45] M. Enomoto, N. Nagaya, M. Uematsu et al., "Cardiovascular and hormonal effects of subcutaneous administration of ghrelin, a novel growth hormone-releasing peptide, in healthy humans," Clinical Science, vol. 105, no. 4, pp. 431-435, 2003.

[46] N. Nagaya, M. Kojima, M. Uematsu et al., "Hemodynamic and hormonal effects of human ghrelin in healthy volunteers," American Journal of Physiology Regulatory, Integrative and Comparative Physiology, vol. 280, no. 5, pp. R1483-R1487, 2001.

[47] C. J. Zhang, M. Bidlingmaier, M. Altaye et al., "Acute administration of acyl, but not desacyl ghrelin, decreases blood pressure in healthy humans," European Journal of Endocrinology, vol. 176, no. 2, pp. 123-132, 2017. 


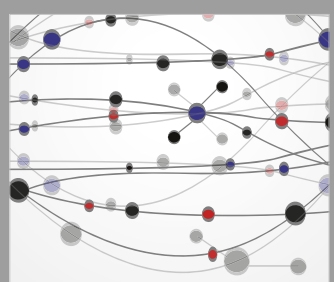

The Scientific World Journal
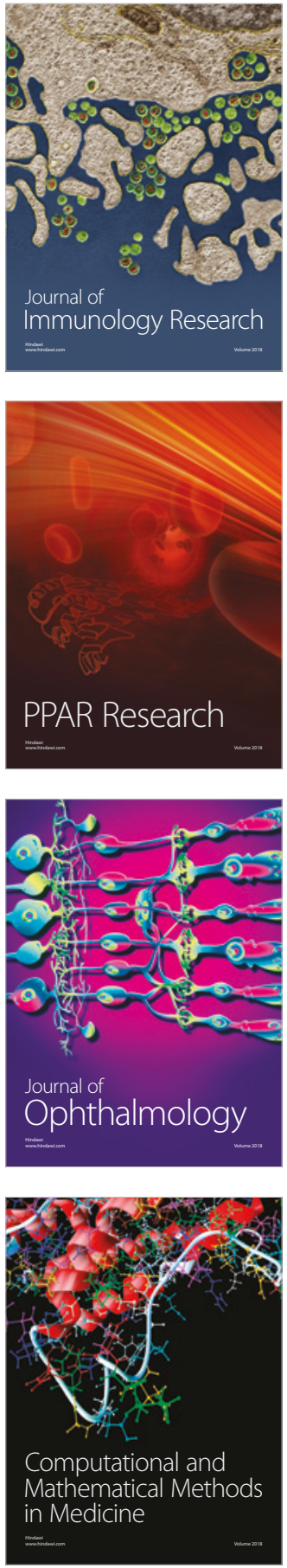

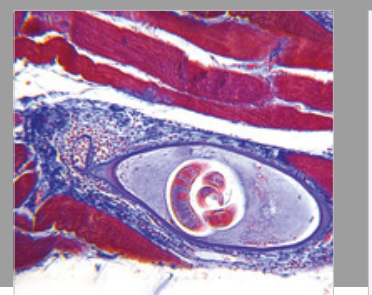

Gastroenterology Research and Practice

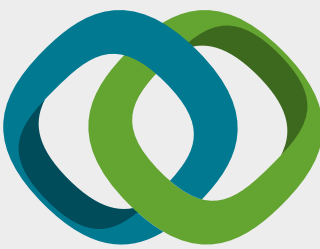

\section{Hindawi}

Submit your manuscripts at

www.hindawi.com
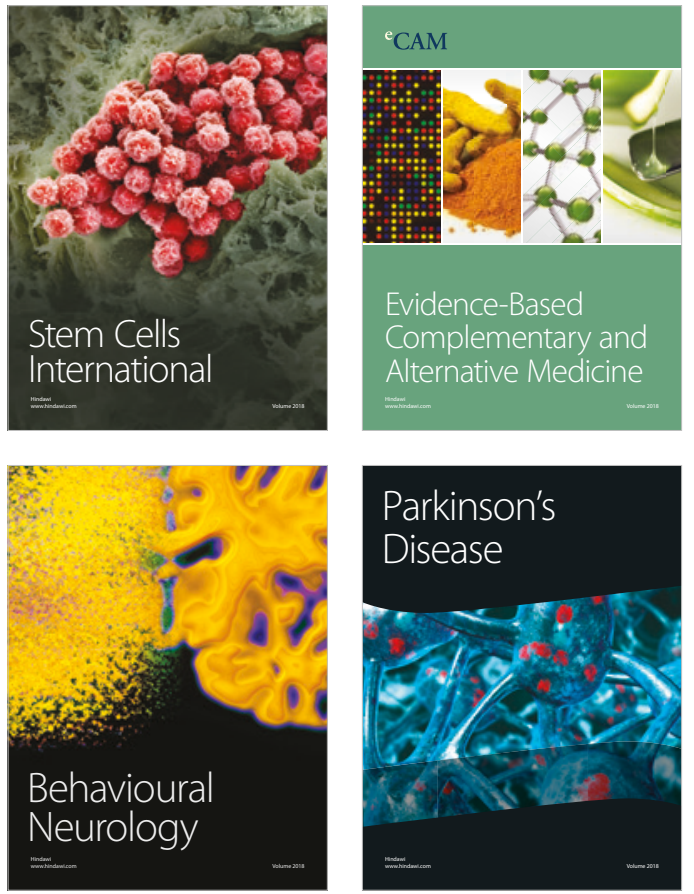

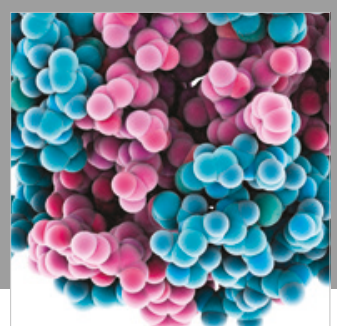

ournal of

Diabetes Research

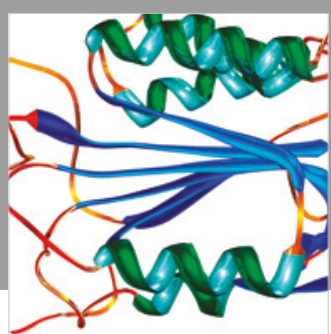

Disease Markers
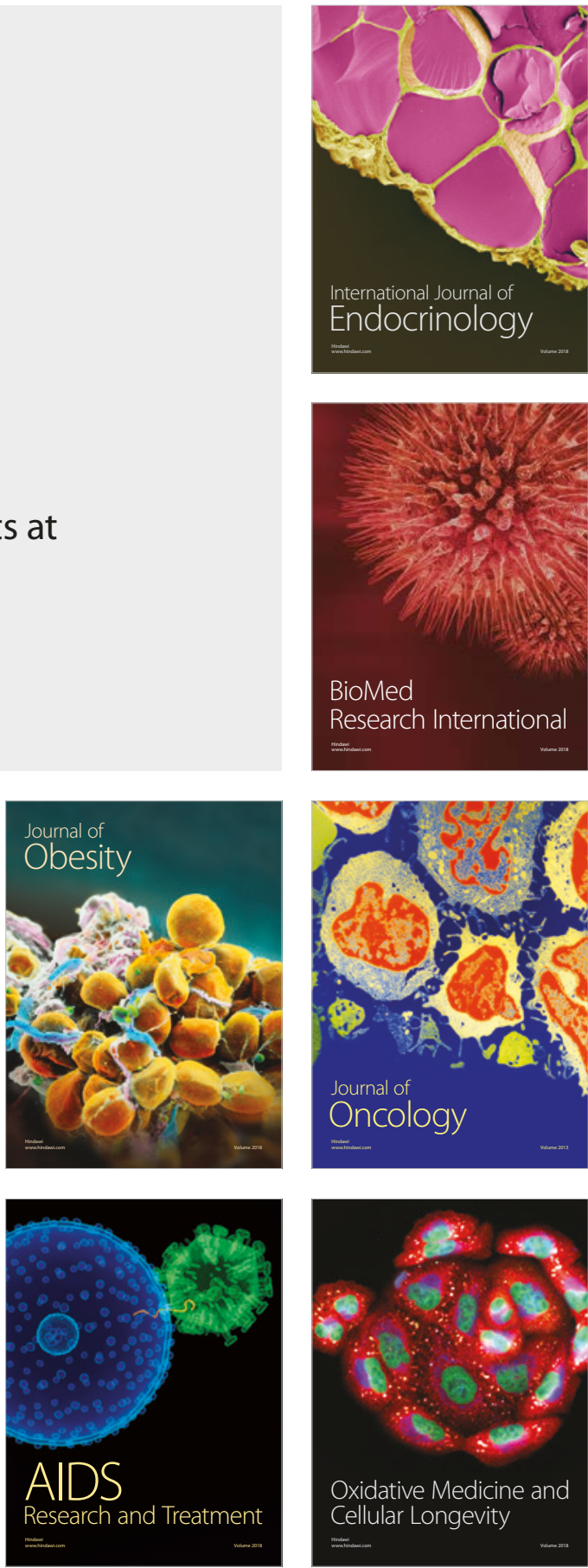